\title{
PREFACE TO THE GERMAN EDITION
}

NeARLy five decades have passed by since Hermann Kopp's classical Geschichte der Chemie ${ }^{1}$ began to appear, and it is now fifteen years since this was followed by the same indefatigable author's Entwickelung der Chemie in der neueren Zeit. ${ }^{2}$

The publication of these comprehensive works, in conjunction with which Höfer's Histoire de la Chimie must be named, and the further descriptions of the growth of chemistry within particular periods given both by Kopp himself and by other writers, might lead one to suppose that there was no pressing need for further work in the same direction at the present time.

This point can, the author thinks, be best discussed by his making a few remarks here with respect to the aim and plan of the present volume.

In this History of Chemistry the attempt bas been made to describe within short compass the development of chemical knowledge, and especially of the general doctrines of chemistry which have thus been gradually evolved, from their earliest beginnings up to the present day. After a

1 " History of Chemistry."

2 "The Development of Chemistry in Recent Times." 
general account of the main directions followed by chemistry in the various ages, the growth of particular branches of the science has been more or less minutely detailed.

In the general descriptions great emphasis has been laid upon the genesis of particular ideas, and their expansion into important dogmas or comprehensive theories. At the same time, in order that a vivid picture of the various periods and their distinguishing characteristics might be presented to the reader, short accounts have been given of the works, and in some cases of the lives, of the men who originated and developed such views.

In the special sections, on the other hand, the attempt has been made to collect together fundamental facts, which have been sifted and relegated to their proper branch of the science, and thus to offer as clear a description as possible of the state of chemical knowledge at the time in question.

That neither in this nor in the history of the development of theoretical views could completeness be thus achieved, hardly requires to be stated. But the author has at all events endeavoured to give a fair synopsis of the most important theories and facts which constitute the foundation of chemistry as we now know it.

The growth of chemical knowledge during recent times, since Boyle, and especially since Lavoisier, naturally forms the principal subject of the following chapters. The author is fully aware of the many difficulties which have to be met here, difficulties which increase in extent the nearer we approach to the history of our own period. We stand too close to the development of the theoretical views of these latter days to feel certain of always preserving the unbiassed 
temperament which is essential to the true historian. But, notwithstanding this, the author has ventured the attempt to carry the record of the history of chemistry up to the present day.

In this task he has done his best to preserve throughout an objective attitude; and he has further been guided by the earnest desire to contribute effectively towards shedding a clear light upon the opposing views held with respect to the development and the importance of the chemical doctrines of to-day. It has also been his duty as an historian to endeavour to apply to the services rendered by eminent investigators of quite recent years a calmer and juster criticism than has hitherto in many cases been meted out to them.

ERNST VON MEYER.

LEIPZIG, Tth October 1888. 
